Japan. J. Med. Sci. Biol., 22, 51-64, 1969

\title{
EPIDEMIOLOGICAL STUDY ON THE PREVENTIVE EFFECT OF THIABENDAZOLE AS AN OVICIDE AGAINST HUMAN HOOKWORM, TRICHURIS AND ASCARIS INFECTIONS
}

\author{
HARUHIKO KUTSUMI \\ Department of Parasitology, National Institute of Health, \\ Shinagawa-ku, Tokyo 141, Japan
}

(Received: November 11th, 1968)

\begin{abstract}
SUMMARY : Epidemiological analyses on the preventive effect of thiabendazole as an ovicide against human helminth infections are described. Thiabendazole was mixed in night-soil once a month during a period from April to October 1964 in the control of hookworm infection, and from June 1964 to March 1966 in the control of Ascaris and Trichuris infections. The findings are as follows: (1) The rate of new infections with hookworms (Necator americanus) in the treated area was two fold lower than that in the non-treated area. (2) The rate of new infections with Trichuris in the treated area was three fold lower than that in the non-treated area. (3) As to the new infections with Ascaris, the rate of patients with fertilized eggs in the treated area was four fold lower than that in the non-treated area. Moreover, new infections were found to occur in groups in the families of the non-treated area, whereas the incidence was sporadic in the treated area.
\end{abstract}

\section{INTRODUCTION}

Chemical treatment of night-soil is one of the effective methods for reducing the number of live helminth eggs in night-soil. A number of chemicals have been tested for this purpose by many workers. Some of them were proved effective only in acidified medium. Since the $\mathrm{pH}$ of night-soil in the storage tanks is usually alkaline, the application of these chemicals was considered to be impractical. Unlike these chemicals, however, thiabendazole was found highly effective both in acid and alkaline night-soil media against the eggs of hookworm, Trichuris and Ascaris (Kutsumi and Komiya, 1965).

As an extention of laboratory tests, the present study deals with the preventive effect of thiabendazole against the human infections with three genera of soil-transmitted helminths; hookworm, Trichuris and Ascaris in the field tests.

\section{MATERIALS AND METHODS}

Study areas and subjects: Effects of the ovicide on the human hookworm and on Trichuris and Ascaris were tested in different areas, not far from Tokyo

A part of this paper was presented at a Eleventh Pacific Science Congress of the Pacific Science Association, held at the University of Tokyo, Japan, August-September 1966, and organized by the Science Council of Japan.

久津見晴彦 (国立予防衛生研究所寄生虫部) 
City. The former was observed in Kusu village located in the center of Saitama Prefecture $50 \mathrm{~km}$ north of Tokyo, and the latter in Hinohara village $70 \mathrm{~km}$ northwest of Tokyo. Kusu village has a population of 2,500 of whom 1,840 residing in 6 of 9 communities were tested; the inhabitants are engaged in the cultivation of rice and vegetable plantations. Hinohara village has a population of 5,000, of whom 900 residing in 6 of 30 communities were tested and most of the inhabitants are forest workers and work sometimes in a small vegetable plantation around their houses.

Chemicals used and night-soil treatment: Thiabendazole was used in the form of water-soluble powder (each gram contains $350 \mathrm{mg}$ of thiabendazole, Lot No. 64RTS54), which was first dissolved in a bucket with water and then mixed in night-soil reservoir or in a lavatory tank of each house. A concentration of the ovicide used was approximately $7 \mathrm{ppm}$ against hookworm eggs in Kusu village and approximately $10 \mathrm{ppm}$ against Trichuris and Ascaris eggs in Hinohara village. The application of the ovicide was performed once a month by the members of a local hygiene committee who knew the method of treatment. The night-soil treated in a reservoir was thoroughly mixed once a day during exposure. After a 7-day exposure, at least, treated night-soil was buried in a pit or used as a fertilizer. During the exposure period, an addition of untreated fresh night-soil was prohibited.

Fecal examinations and epidemiological survey: For the detection of hookworm eggs in fecal materials, sodium sulfate-brine floatation method $(290 \mathrm{~g}$ of $\mathrm{NaCl}$, $185 \mathrm{~g}$ of $\mathrm{Na}_{2} \mathrm{SO}_{4}$ dissolved in $1,000 \mathrm{ml}$ of water) was used and three specimens were examined on each person. Trichuris and Ascaris eggs in feces were detected by fecal examination with Kato's thick smear method (Kato and Miura, 1954 ; Kato, 1960 ; Komiya et al., 1960 ; Martin and Beaver, 1967). Ascaris eggs found were recorded as fertilized or unfertilized. Mean number of eggs was obtained by the egg-count on three direct smear preparations (Ishizaki, 1953). Moreover, a questionaire was sent to each family to note the age, sex, occupation and frequency of works in the vegetable plantation of each member and the method of night-soil disposal and whether they have rice and vegetable plantations or not. The results obtained from this survey and the findings of fecal examinations were recorded on a punch card prepared for each individual.

\section{RESUlTS}

\section{Effect of Thiabendazole Treatment on a Hookworm Infestation Area}

For the study on hookworm infection, Kusu village was divided into two areas, treated and non-treated. The application of the ovicide was undertaken once a month during a period from May to October 1964, which corresponds to the period of frequent occurrence of natural hookworm infection. Fecal examinations were performed in March and August 1964, and March 1965.

Anthelmintic treatment of hookworm carriers with 1-bromo-2-naphthol, "Wormin", was carried out after completion of 6 month-application of the ovicide. Although the cure rate was slightly higher in the treated area $(82.9 \%, 90 / 109)$ than in the non-treated area $(72.4 \%, 71 / 98)$, the average number of worms ex- 
pelled per patient was quite similar in both the areas (10.1 and 10.5). These results showed that the experimental conditions in both the areas were affected equally by the anthelmintic treatment.

\section{Epidemiological Status of the Subjects before the Ovicidal Treatment:}

The samples in the two areas were almost similar in their epidemiological characters, i. e., sex ratio, age distribution and rate of hookworm infection. As shown in Table 1 , the rate of hookworm infection was very low in the minors $(6.5 \%, 32 / 496)$, and high in the adults $(28.5 \%, 253 / 888)$. Such a low rate of carriers in the minors may be attributable to no or less frequent engagement of them $(9.1 \%, 45 / 496)$ in the vegetable plantation as compared with the adults $(70.4 \%, 625 / 888)$. From the results mentioned above, individuals of these two groups, minors and adults, were separately analyzed in relation to new infection in the epidemiological study.

Table 1. Number of hookworm carriers in relation to age and working condition before treatment

\begin{tabular}{|c|c|c|c|c|c|c|}
\hline \multirow{4}{*}{$\begin{array}{l}\text { Working } \\
\text { condition }\end{array}$} & \multirow{4}{*}{ Area } & \multicolumn{5}{|c|}{ Age group } \\
\hline & & \multicolumn{3}{|c|}{$\begin{array}{l}\text { Minor } \\
\text { (19 years and under) }\end{array}$} & \multicolumn{2}{|c|}{$\begin{array}{c}\text { Adult } \\
\text { (20 years and over) }\end{array}$} \\
\hline & & \multirow{2}{*}{$\begin{array}{c}\text { No. } \\
\text { examined }\end{array}$} & \multicolumn{2}{|c|}{ Carriers } & \multirow{2}{*}{$\begin{array}{l}\text { No. } \\
\text { examined }\end{array}$} & Carriers \\
\hline & & & No. & $\%$ & & No. $\%$ \\
\hline \multirow{3}{*}{$\begin{array}{l}\text { Working in } \\
\text { plantation }\end{array}$} & Treated & 15 & 1 & 6.7 & 293 & $\begin{array}{ll}94 & 32.1\end{array}$ \\
\hline & Non-treated & 30 & 1 & 3.3 & 332 & $115 \quad 34.6$ \\
\hline & Total & 45 & 2 & 4.4 & 625 & $209 \quad 33.4$ \\
\hline \multirow{3}{*}{$\begin{array}{l}\text { No working in } \\
\text { plantation }\end{array}$} & Treated & 220 & 20 & 9.1 & 144 & $20 \quad 13.9$ \\
\hline & Non-treated & 231 & 10 & 4.3 & 119 & $24 \quad 20.2$ \\
\hline & Total & 451 & 30 & 6.7 & 263 & $\begin{array}{ll}44 & 16.7\end{array}$ \\
\hline Grand total & & 496 & 32 & 6.5 & 888 & $253 \quad 28.5$ \\
\hline
\end{tabular}

\section{An Intermediate Fecal Examination:}

For the analysis of new infection, an intermediate fecal examination was carried out in August 1964, corresponding to the three months after initiation of night-soil treatment. The results did not reflect the full efficacy of the ovicide, because there may have been possible infections due to hookworm larvae preexisting in the field without being affected by the ovicide.

The results are shown in Fig. 1. Positive and negative conversion rates, referred to hereafter as $\mathrm{PC}$ and $\mathrm{NC}$ rates, indicate the rate of persons who turned from negative to positive for eggs and vice versa, respectively. PC rate decreased and $\mathrm{NC}$ rate increased as the frequency of working in the plantation decreased. The above-mentioned correlations, however, were not observed among minors. Thus, the result obtained from the minors was excluded from the final epidemiological analysis on the occurrence of the new infection. 


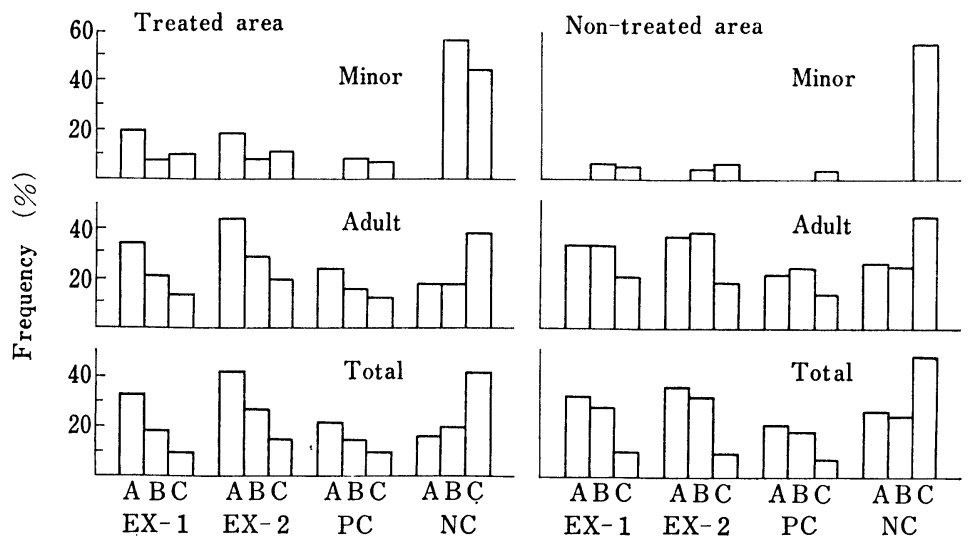

Fig. 1. Comparison of the results by the fecal examinations for hookworm eggs among minors, adults and total populations.

$\mathrm{A}, \mathrm{B}$ and $\mathrm{C}$ : Frequent, less frequent and no working in plantation, respectively.

EX-1 and EX-2: Hookworm carriers in the first and second fecal examinations, respectively.

PC and NC: Positive and negative conversion, respectively, observed in the second fecal examination.

\section{Epidemiological Analysis of the Results:}

According to the final fecal examination in March 1965, PC rate was higher in the non-treated area than that in the treated area (Table 2). In this instance, no difference in sex ratio, age distribution and working condition was observed between the PC cases in these areas. Occurrence of PC cases was analyzed on the basis of the epidemiological difference of family and individual groups (Table 3). In the treated area, PC cases were observed in $11.0 \%$ of the families with hookworm carriers, $11.3 \%$ of these having vegetable plantation and $13.6 \%$ of these using night-soil as a fertilizer directly or as a manure heap. On the contrary, in the non-treated area, PC cases were observed in $23.3 \%, 20.9 \%$ and $30.3 \%$, respectively. PC rate, however, was not different in both the areas among the families having no carriers, those having no vegetable plantation, and those bury-

Table 2. Positive conversion cases of hookworm in the final fecal examination

\begin{tabular}{|c|c|c|c|c|c|c|}
\hline \multirow{3}{*}{ Group } & \multicolumn{3}{|c|}{ Treated area } & \multicolumn{3}{|c|}{ Non-treated area } \\
\hline & \multirow{2}{*}{$\begin{array}{c}\text { No. } \\
\text { examined }\end{array}$} & \multicolumn{2}{|c|}{ PC case } & \multirow{2}{*}{$\begin{array}{c}\text { No. } \\
\text { examined }\end{array}$} & \multicolumn{2}{|c|}{ PC case } \\
\hline & & No. & $\%$ & & No. & $\%$ \\
\hline Adult & 365 & 21 & 5.8 & 357 & 33 & 9.2 \\
\hline Minor & 213 & 4 & 1.9 & 249 & 5 & 2.0 \\
\hline Total & 578 & 25 & 4.3 & 606 & 38 & 6.3 \\
\hline
\end{tabular}


Table 3. Positive conversion cases of hookworm in the family- and individual-groups in relation to their epidemiological status

\begin{tabular}{|c|c|c|c|c|c|c|c|c|c|}
\hline \multirow{3}{*}{\multicolumn{2}{|c|}{$\begin{array}{l}\text { Epidemiological } \\
\text { status of family }\end{array}$}} & \multicolumn{4}{|c|}{ Family-group } & \multicolumn{4}{|c|}{ Individual-group } \\
\hline & & \multicolumn{2}{|c|}{$\begin{array}{c}\text { Treated } \\
\text { area }\end{array}$} & \multicolumn{2}{|c|}{$\begin{array}{l}\text { Non-treated } \\
\text { area }\end{array}$} & \multicolumn{2}{|c|}{$\begin{array}{c}\text { Treated } \\
\text { area }\end{array}$} & \multicolumn{2}{|c|}{$\begin{array}{l}\text { Non-treated } \\
\text { area }\end{array}$} \\
\hline & & PC/Total & $\%$ & PC/Total & $\%$ & PC/Total & $\%$ & PC/Total & $\%$ \\
\hline \multirow{2}{*}{$\begin{array}{l}\text { Pre-existence } \\
\text { of carriers }\end{array}$} & Yes & $12 / 109$ & 11.0 & $24 / 103$ & 23.3 & $15 / 258$ & 5.8 & $27 / 246$ & 11.0 \\
\hline & No & $6 / 61$ & 9.8 & $5 / 47$ & 10.6 & $6 / 136$ & 4.4 & $6 / 126$ & 4.8 \\
\hline \multirow{2}{*}{$\begin{array}{l}\text { Presence of } \\
\text { vegetable } \\
\text { plantations }\end{array}$} & Yes & $15 / 133$ & 11.3 & $27 / 129$ & 20.9 & $17 / 322$ & 5.3 & $30 / 332$ & 9.0 \\
\hline & No & $3 / 37$ & 8.1 & $2 / 21$ & 9.5 & $4 / 72$ & 5.6 & $3 / 40$ & 7.5 \\
\hline \multirow{2}{*}{$\begin{array}{l}\text { Use of night- } \\
\text { soil as a } \\
\text { fertilizer }\end{array}$} & Yes & $9 / 66$ & 13.6 & $20 / 66$ & 30.3 & $10 / 141$ & 7.1 & $21 / 167$ & 12.5 \\
\hline & No & $9 / 104$ & 8.4 & $9 / 84$ & 10.7 & $11 / 224$ & 4.9 & $12 / 193$ & 6.2 \\
\hline
\end{tabular}

ing night-soil into a pit. It is clear that the PC rate was two fold higher in the non-treated area than that in the treated area in the families having more chances of infection. Similar tendencies were obtained in the individual groups derived from above-mentioned families.

It is concluded that an application of thiabendazole resulted in reduction of hookworm infections by approximately $50 \%$ as compared with that in the nontreated area.

\section{The NC Rate:}

NC rate was observed on the individuals receiving no anthelmintic treatment. As shown in Table 4, NC rate in the adults of the treated area was much higher in the second period (47.5\%, October $1964-$ March 1965) than that in the first period (28.3\%, March-August 1964). NC rate in the non-treated area, however, was nearly identical $(42.4 \%$ and $42.8 \%$ ) in both periods. Occurrence of NC cases is clearly demonstrated in the area where a new infection hardly occurs. Therefore, the results mentioned above showed a lower chance for new infections to occur in the treated area.

Table 4. Negative conversion cases in the hookworm carriers who received no anthelmintics

\begin{tabular}{|c|c|c|c|c|c|c|c|}
\hline \multirow{3}{*}{$\begin{array}{l}\text { Period of } \\
\text { examination }\end{array}$} & \multirow{3}{*}{ Subjects } & \multicolumn{3}{|c|}{ Treated area } & \multicolumn{3}{|c|}{ Non-treated area } \\
\hline & & \multirow{2}{*}{$\begin{array}{c}\text { No. } \\
\text { examined }\end{array}$} & \multicolumn{2}{|c|}{ NC case } & \multirow{2}{*}{$\begin{array}{c}\text { No. } \\
\text { examined }\end{array}$} & \multicolumn{2}{|c|}{ NC case } \\
\hline & & & No. & $\%$ & & No. & $\%$ \\
\hline $\begin{array}{l}\text { First period } \\
\text { (March - August, } \\
\text { 1964) }\end{array}$ & Adult & 46 & 13 & 28.3 & 59 & 25 & 42.4 \\
\hline $\begin{array}{l}\text { Second period } \\
\text { (October 1964- } \\
\text { March 1965) }\end{array}$ & Adult & 59 & 28 & 47.5 & 70 & 30 & 42.8 \\
\hline
\end{tabular}




\section{Effect of Thiabendazole Treatment on a Trichuris Infestation Area}

After the first fecal examination (July 1964), five examinations were carried out after every four months. The application of the ovicide was undertaken once a month during the period of 22 months starting on June 1964 and terminating on March 1966. PC rate was studied separately in the first period (July 1964 April 1965) and the second period (May 1965-March 1966) with the following consideration. As the PC rate may be influenced by pre-existing eggs surviving in the plantation before treatment, the period of survival of Trichuris eggs in the plantation was regarded as being about ten months after that of Asaaris eggs (Komiya, Izumi and Ito, 1955). As the pre-existing eggs are supposed to have died by April 1965, the PC cases due to pre-existing eggs may not have occurred after this period. Therefore, the results of the fecal examination in July 1965 and later, which correspond to the second period, were used for the evaluation of efficacy of the ovicidal agent.

\section{Epidemiological Analysis of the Results:}

The rates of Trichuris carriers before and after the treatment are shown in Table 5. According to the final fecal examination on March 1966, the rate of carriers were $47.1 \%$ in the treated area and $42.6 \%$ in the non-treated area. It decreased by $18 \%$ in the treated area but no significant changes were noted in the non-treated area. As the final results are obtained from a net balance of PC and NC cases, an analysis of each rate was made from the similar standpoint to the one in the previous chapter on hookworm infections.

Table 5. Rates of Trichuris carriers before and after treatment

\begin{tabular}{|c|c|c|c|c|c|c|c|}
\hline \multirow{3}{*}{\multicolumn{2}{|c|}{$\begin{array}{l}\text { Subjects and date } \\
\text { of examination }\end{array}$}} & \multicolumn{3}{|c|}{ Treated area } & \multicolumn{3}{|c|}{ Non-treated area } \\
\hline & & \multirow{2}{*}{$\begin{array}{c}\text { No. } \\
\text { examined }\end{array}$} & \multicolumn{2}{|c|}{ Carriers } & \multirow{2}{*}{$\begin{array}{c}\text { No. } \\
\text { examined }\end{array}$} & \multicolumn{2}{|c|}{ Carriers } \\
\hline & & & No. & $\%$ & & No. & $\%$ \\
\hline \multicolumn{8}{|c|}{ Before treatment } \\
\hline \multirow{2}{*}{ Age } & Minor & 166 & 94 & 56.6 & 135 & 52 & 38.5 \\
\hline & Adult & 237 & 168 & 70.9 & 194 & 98 & 50.5 \\
\hline \multirow{2}{*}{ Sex } & Male & 193 & 121 & 62.7 & 165 & 71 & 43.3 \\
\hline & Female & 210 & 141 & 67.1 & 105 & 79 & 40.9 \\
\hline \multicolumn{2}{|l|}{ Total } & 403 & 262 & 65.0 & 329 & 150 & 45.6 \\
\hline \multicolumn{8}{|c|}{ After treatment } \\
\hline \multirow{3}{*}{ First period } & (July 1964 & 403 & 262 & 65.0 & 329 & 150 & 45.6 \\
\hline & November 1964 & 403 & 258 & 64.0 & 329 & 134 & 40.7 \\
\hline & ( March 1965 & 403 & 285 & 70.0 & 329 & 151 & 45.9 \\
\hline \multirow{3}{*}{ Second period } & ( July 1965 & 403 & 258 & 64.0 & 329 & 149 & 45.3 \\
\hline & $\{$ November 1965 & 403 & 224 & 55.6 & 329 & 134 & 40.7 \\
\hline & ( March 1966 & 403 & 190 & 47.1 & 329 & 140 & 42.6 \\
\hline
\end{tabular}


The PC Rate:

The PC rates in the subjects successively negative for eggs were $28.5 \%$ and $25.1 \%$ in the first and second periods, respectively, in the non-treated area (Fig. 2). On the other hand, the $\mathrm{PC}$ rate in the treated area decreased from $38.4 \%$ to $10.6 \%$. The results reveal that the $\mathrm{PC}$ rate in the first period was proportional to the rate of carriers in the first fecal examination in each area, because the effect of the ovicide may not have been manifested in the first period. In the second period, however, it is clear that the infection with Trichuris might have been suppressed by the use of the ovicide in the treated area.

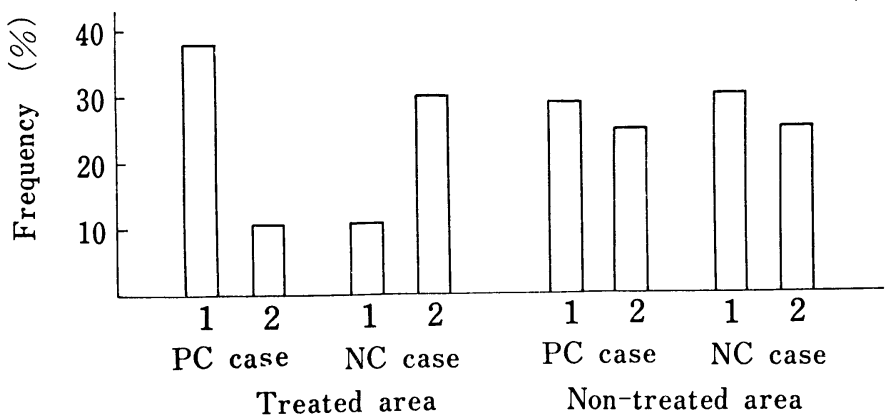

Fig. 2. The rates of positive and negative conversion cases of Trichuris from negative and positive cases, respectively in the first and second periods of examination.

1: First period. 2: Second period.

Furthermore, this fact may also be explained from the results that the PC rates in the second period were $10.6 \%$ in the originally negative cases and $15.6 \%$ in the $\mathrm{NC}$ cases of the treated area, while the corresponding values were $25.1 \%$ and $39.0 \%$ in the non-treated area, the last two values being more than twice as high as the formers (Table 6).

\section{The NC Rate:}

Trichuris carriers were examined for the $\mathrm{NC}$ rate, since there is a possibility of natural exclusion of the worms from a carrier. Figure 2 shows that the $\mathrm{NC}$ rate

Table 6. Positive conversion cases of Trichuris in the second period of examination

\begin{tabular}{|c|c|c|c|c|c|c|}
\hline \multirow{3}{*}{ Subjects } & \multicolumn{3}{|c|}{ Treated area } & \multicolumn{3}{|c|}{ Non-treated area } \\
\hline & \multirow{2}{*}{$\begin{array}{l}\text { No. } \\
\text { examined }\end{array}$} & \multicolumn{2}{|c|}{ PC case } & \multirow{2}{*}{$\begin{array}{c}\text { No. } \\
\text { examined }\end{array}$} & \multicolumn{2}{|c|}{ PC case } \\
\hline & & No. & $\%$ & & No. & $\%$ \\
\hline Originally negative case & 141 & 15 & 10.6 & 179 & 45 & 25.1 \\
\hline NC case & 83 & 13 & 15.6 & 77 & 30 & 39.0 \\
\hline Total & 224 & 28 & 12.4 & 256 & 75 & 29.3 \\
\hline
\end{tabular}


in the treated area was $10.3 \%$ in the first and $29.4 \%$ in the second period, indicating a threefold increase in the latter, while the rates were unchanged in both periods in the non-treated area. The results suggest a less frequent occurrence of new infections with Trichuris in the treated area than in the non-treated area.

The results mentioned above showed that the ovicidal treatment of night-soil suppressed at least $50 \%$ of new infections with Trichuris.

\section{Effect of Thiabendazole Treatment on Ascaris Infestation Area}

An experimental area of Hinohara village was divided into three, treated area A (treated with ovicide and anthelmintic), treated area B (treated with ovicide but not with anthelmintic) and non-treated area (non-treated with ovicide but treated with anthelmintic). Fecal examinations were performed in July and November 1964, March, July and November 1956 and March 1966. The application of the ovicide was undertaken once a month during the period of 22 months starting on June 1964 and terminating on March 1966.

Anthelmintic treatment of Ascaris carriers was performed in April 1965, the end of the first period, with a combined preparation of Santonin and kinic acid in the treated $A$ and non-treated areas. The cure rates were $70.7 \%(29 / 41)$ and $75.0 \%(36 / 48)$ in the treated $A$ and non-treated areas, respectively.

On the Fate of Ascaris Eggs in the Field:

As the experimental conditions were different among those three areas, consideration was made on the number of live and dead eggs in the field before and after use of the ovicide.

Treated area A (treated with ovicide and anthelmintic): After use of the ovicide (June 1964), the eggs discharged from Ascaris carriers have been treated with the ovicide. All the pre-existing eggs in the field before treatment are supposed to have died by April 1965, because the survival period of eggs is estimated to be about 10 months (Komiya, Izumi and Ito, 1955). The number of eggs discharged from the carriers decreased in April 1965 by the treatment with anthelmintic.

Treated area B (treated with ovicide but not with anthelmintic): In this area discharged eggs will die after the use of the ovicide. Since no anthelmintic is used, the total number of discharged eggs would remain unchanged throughout the period of experiment. However, surviving eggs pre-existing in the field will die gradually in about 10 month-period.

Non-treated area (non-treated with ovicide but treated with anthelmintic) : Since no ovicide is used in this area, the eggs pre-existing in the field are surviving eggs and those from the carriers are freely distributed. Use of the anthelmintic decreases the number of Ascaris carriers so that the number of discharged eggs are decreased. Surviving eggs will gradually disappear during a period of about 10 months.

According to the above reasons, it was clear that the rate of new infections in the first period (first 10 months after starting application of the ovicide) should be separately studied from that in the second period (further 12 months). The PC cases in the first period may possibly have occurred by the pre-existing eggs before treatment, and are not good for evaluation of the preventive effect of the 
ovicide. Thus, the effect of the treatment was evaluated by the results obtained in the second period.

The Results and Their Epidemiological Analysis:

As shown in Table 7, the final fecal examination revealed that the rate of Ascaris carriers decreased to one-half of the initial level in the treated area A and to two-thirds in the treated area B. In the non-treated area, it showed only a slight decrease as compared with that of the treated areas.

Table 7. Rates of Ascaris carriers before and after treatment

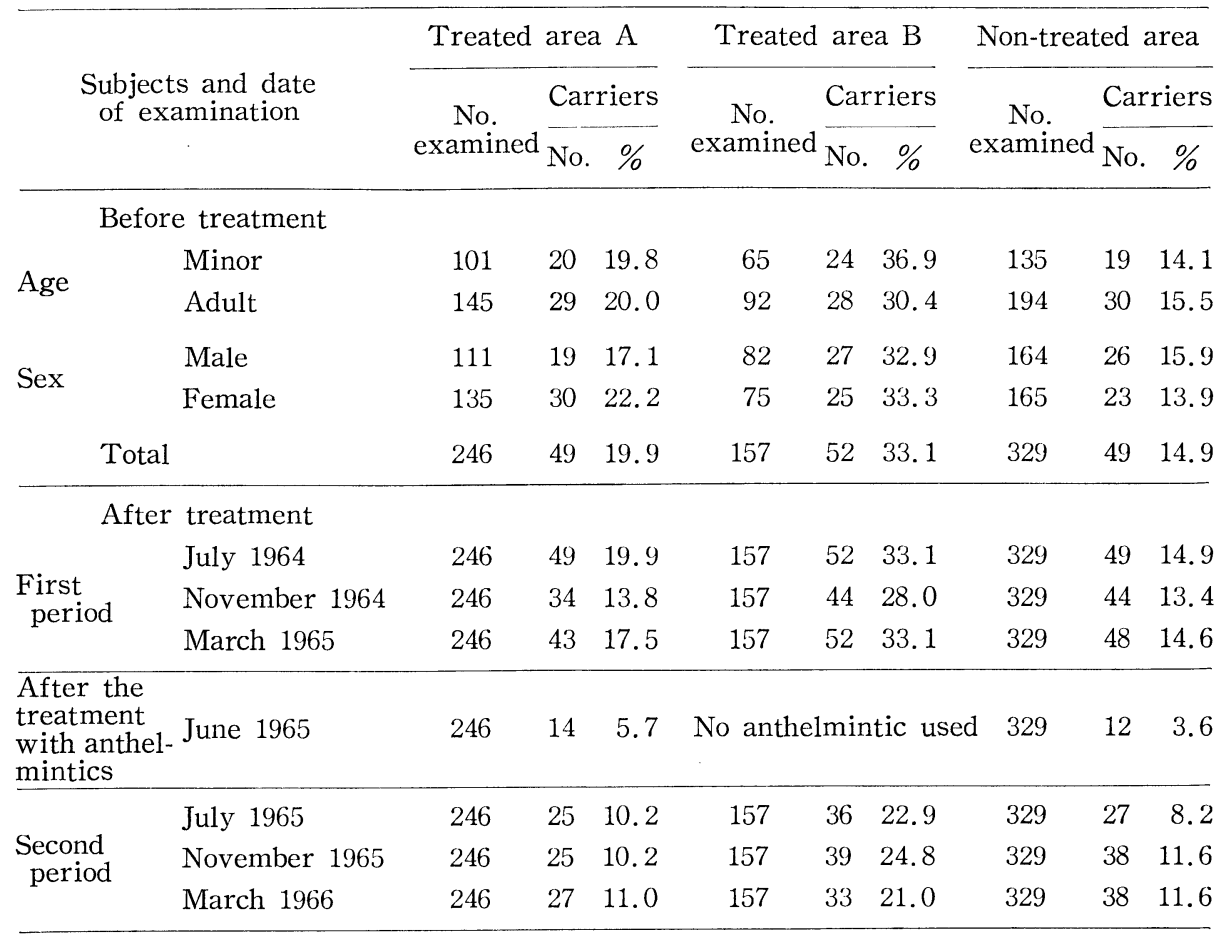

Epidemiologically it is worth while to notice whether PC cases discharge fertilized or unfertilized Ascaris eggs. Changes of eggs detected in the fecal examination from unfertilized to fertilized probably signifies a new infection. No subjects who discharged at first unfertilized eggs and later fertilized eggs were found in the treated area $\mathrm{A}$, one case $(1 / 17,5.9 \%)$ in the treated area $\mathrm{B}$, and 4 cases $(4 / 25 ; 16.0 \%)$ in the non-treated area. Finally, as shown in Table $8,10.7 \%$ $(3 / 28)$ and $11.2 \%(2 / 18)$ of the PC cases discharged fertilized eggs in the treated areas $\mathrm{A}$ and $\mathrm{B}$, respectively. In the non-treated area fertilized eggs were observed in $48.8 \%(20 / 41)$ of PC cases, being four times as high as that in both the treated areas. The ratio of persons discharging unfertilized eggs to those with fertilized eggs in the PC cases was $8: 1(25: 3$ and 16:2) in the treated area A and B, and $1: 1(21: 20)$ in the non-treated area. Intensity of infection was analyzed by the egg-count with the direct smear method (average number of eggs in three 
Table 8. Positive conversion cases of Ascaris in relation to the number of fertilized (F) and unfertilized (U) eggs in the second period of examination

\begin{tabular}{|c|c|c|c|c|c|c|c|}
\hline \multirow{2}{*}{ Subjects } & \multirow{2}{*}{$\begin{array}{l}\text { No. of } \\
\text { eggs* }\end{array}$} & \multicolumn{2}{|c|}{ Treated area A } & \multicolumn{2}{|c|}{ Treated area $\mathrm{B}$} & \multicolumn{2}{|c|}{ Non-treated area } \\
\hline & & $\mathrm{F}$ & $\mathrm{U}$ & $\mathrm{F}$ & $\mathrm{U}$ & $\mathrm{F}$ & $\mathrm{U}$ \\
\hline \multirow{4}{*}{ PC cases } & $1-9$ & 1 & 19 & 0 & 12 & 3 & 20 \\
\hline & $10-49$ & 2 & 6 & 2 & 3 & 13 & 1 \\
\hline & $50-$ & 0 & 0 & 0 & 1 & 4 & 0 \\
\hline & Total & 3 & 25 & 2 & 16 & 20 & 21 \\
\hline
\end{tabular}

* Number of eggs shows an average number of eggs in three fecal specimens, each of which contains approximately $3 \mathrm{mg}$ of feces.

fecal specimens : Ishizaki, 1953). No significant differences were noted among the three areas in the egg-count distribution of cases with unfertilized eggs. However, subjects with more than 50 fertilized eggs were observed only in the non-treated area. Moreover, in the second period, $26 \%(8 / 31)$ of the infected cases in the non-treated area showed an increase in the number of eggs, but only $5 \%(1 / 21)$ and $6 \%(2 / 31)$ in the treated areas $\mathrm{A}$ and $\mathrm{B}$, respectively (Fig. 3).

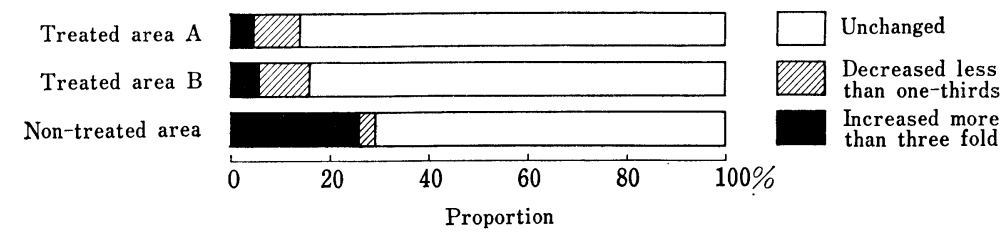

Fig. 3. Comparison of the results obtained from egg-count on Ascaris carriers in the second period of examination.

Finally the number of PC cases in a family is shown in Fig. 4. Occurrence of more than $2 \mathrm{PC}$ cases in one family was seen in $19 \%(5 / 27)$ of the total families with $\mathrm{PC}$ cases in the non-treated area, indicating a considerably higher rate than $4 \%(1 / 27)$ and $6 \%(1 / 16)$ in the treated areas. Thus, the total number of PC cases found in the families mentioned above occupied $39 \%(19 / 49)$ of the total $\mathrm{PC}$ cases in the non-treated area, being also higher than $11 \%(4 / 37)$ and $14 \%$ $(3 / 21)$ in the treated areas. These data indicated that new infections occurred in groups in families of the non-treated area, whereas it occurred sporadically in the treated areas.

From these results, thiabendazole is considered to have a protective efficacy against Ascaris infection. The efficacy is not clearly demonstrated by the rate of new infections, but has been shown rather clearly by the epidemiological analyses. Among the PC cases in the treated areas, about $90 \%(25 / 28$ and 16/18) discharged unfertilized Ascaris eggs (Table 8), which cannot become a source of reinfection. In the non-treated area, about $50 \%(20 / 41)$ discharged fertilized eggs. Those people probably have a large number of parasites and may become hazardous in public health. 


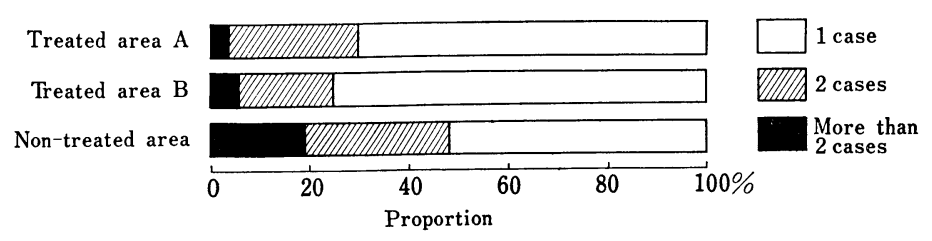

Fig. 4. Proportion of the families in which positive conversion cases of Ascaris occurred in the second period of examination.

\section{DISCUSSION}

The infection with soil-transmitted helminths is influenced by several ecological factors of the host: age, sex, frequency of field-working of individuals and a manner of night-soil disposal in a household. Factors influencing the infection with soil-transmitted helminths may involve host, parasite and environmental conditions.

\section{Host Factors.}

Of the host factors, the age may be a principal one in the epidemiology of Necator americanus infections, since adult person may have more chances to contact with infective larvae in the farm soil. Actually, the rate of hookworm infection in the adults was $33.7 \%(209 / 625)$, being eight fold higher than that in the minors $(4.4 \%, 2 / 45)$ in the group working in the plantation. These results may be closely related to the fact that the rate of engagement of the adults in the vegetable plantation $(70.4 \%, 625 / 888)$ was eight fold higher than that of the minors (9.1\%, 45/496).

However, as seen in Tables 5 and 7, the infections with Trichuris and Ascaris may take place at random in the population regardless of their age. Thus, epidemiological analyses on new infections with those two species of nematode were performed on the whole age groups, but those with hookworms only on the adults. There is no difference between both sexes as to the infection rates with these nematodes.

\section{Parasite Factors.}

When a helminth infection is endemic in a community, its incidence will largely depend upon the chance and place of the infection, and the amount of discharged eggs or larvae. Actually in the case of hookworm diseases, new infections frequently occurred in the family having vegetable plantation manured with night-soil containing eggs discharged by carriers, as shown by the results obtained from the non-treated area (Table 3). But the incidence of new infections in the families mentioned above was very low in the treated area.

The efficacy of the ovicide when determined by the $\mathrm{PC}$ rate was not as clear for Ascaris as seen in Trichuris infection. The difference between the PC rates with Ascaris and Trichuris in this experiment may be explained by the stronger resistance of the former eggs to desiccation and chemicals (Kutsumi and Komiya, 1965). The NC rate, an index of ovicidal efficacy, was much higher in Ascaris carriers $(60 \%)$ than in Trichuris carriers $(35 \%)$. This may be explained by the longer life-span of Trichuris worms in the host (Watson, 1960). 


\section{Environmental Factors.}

The main environmental factors in this experiment are the amount of eggs distributed in the field and the rate of carriers among a population prior to the use of the ovicide. Before the experiment, live Ascaris and Trichuris eggs already scattered in the fields were so large in number that the infections caused by these eggs were inevitable and presumably disturbed the experimental results. By a theoretical assumption, the life-span of these eggs is said to be about 10 months (Komiya, Izumi and Ito, 1955). Infections occurring after this period of 10 months, therefore, may indicate the real efficacy of the ovicidal agent, because of the absence of live eggs in the treated area and presence of live eggs in the non-treated area. This is the reason why the results of examinations in the first period (10 months) were not used. The results obtained from the examinations in the second period have been able to elucidate the practical value of the present ovicidal agent, thiabendazole.

Data obtained from the present experiments on Trichuris and Ascaris infections showed that new infections were not influenced by the epidemiological status of the subjects. For example, sex and age distributions of carriers before treatment as well as the PC cases which occurred were almost similar to those of the total subjects, and no correlation was observed between the frequency of work in the plantation and the PC rate with Trichuris and Ascaris. Moreover, the PC rates of Trichuris infection in the families consuming house-made vegetable and in those which purchase them were $19.4 \%(40 / 206)$ and $21.3 \%(42 / 197)$, respectively, in the treated area, and $36.2 \%(71 / 196)$ and $38.3 \%(51 / 133)$, respectively, in the non-treated area. This tendency in the case of Ascaris infections accords with those of Trichuris infections. These facts may indicate that opportunities for Trichuris and Ascaris infections are equal for all inhabitants in the area.

Inasmuch as the infections with Trichuris and Ascaris occurred uniformly or randomly in a population, and hookworm infections occurred mainly in agricultural workers, it is plausible to expect the preventive effect of the ovicide against these nematode infections.

\section{Assessment of the Efficacy of Ovicides.}

At the end of the first observation period, the treated area $\mathrm{B}$ had still a high rate of Ascaris carriers such as $33 \%$ (Table 7), because no anthelmintic was used, while the rate of carriers in the treated area A was reduced from $20 \%$ to $6 \%$ by the use of anthelmintic. Therefore, the number of eggs discharged to the field in the treated area $\mathrm{B}$ may have been more than five times greater than that of the treated area $\mathrm{A}$ in the second period. Even though the number of eggs distributed in the field were different depending upon each area, those eggs might have been killed by the use of the ovicidal agent, equal rate of new infections being expected in both the treated areas. From the results obtained in the second period, the conditions after treatment were almost the same in both the areas. This result may indicate the sole efficacy of the ovicide in the treated area B contaminated with the huge number of eggs.

As already stated, anthelmintic was applied in the studies on hookworm and Ascaris infections. No anthelmintic, however, was employed in the Trichuris infection, so that a long-term observation on the natural condition of Trichuris 
Table 9. Results of the long-term observation on the natural condition of Trichuris infection in the non-treated area

\begin{tabular}{|c|c|c|c|c|c|c|c|c|}
\hline \multirow{2}{*}{\multicolumn{2}{|c|}{$\begin{array}{l}\text { Date of } \\
\text { examination }\end{array}$}} & Carriers & \multicolumn{2}{|r|}{ PC cases } & \multicolumn{2}{|c|}{$\begin{array}{l}\text { Duration of infec- } \\
\text { tion in PC cases }\end{array}$} & \multicolumn{2}{|c|}{$\begin{array}{l}\text { NC case in } \\
\text { the carrier and } \\
\text { PC case }\end{array}$} \\
\hline & & No. $(\%)$ & No. & $(\%)$ & $\begin{array}{c}<8 \\
\text { months }\end{array}$ & $\begin{array}{c}8 \\
\text { months }<\end{array}$ & No. & $(\%)$ \\
\hline & July 1964 & $150(45.6)$ & & \multirow[b]{2}{*}{$551 / 179(28.5)$} & \multirow[b]{2}{*}{$25(49.0)$} & \multirow[b]{2}{*}{$26(51.0)$} & & \\
\hline $\begin{array}{l}\text { First } \\
\text { period }\end{array}$ & $\begin{array}{l}\text { November } 1964 \\
\text { March } 1965\end{array}$ & $\begin{array}{l}134(40.7) \\
151(45.9)\end{array}$ & $\left.\begin{array}{l}23 \\
28\end{array}\right\}$ & & & & \multicolumn{2}{|c|}{$\left.\begin{array}{l}39 \\
11\end{array}\right\} 50 / 150(33.3)$} \\
\hline $\begin{array}{l}\text { Second } \\
\text { period }\end{array}$ & $\left\{\begin{array}{l}\text { July } 1965 \\
\text { November } 1965 \\
\text { March } 1966\end{array}\right.$ & $\begin{array}{l}149(45.3) \\
134(40.7) \\
140(42.6)\end{array}$ & $\left.\begin{array}{l}32 \\
19 \\
24 *\end{array}\right\}$ & $75 / 256(29.3)$ & $22(43.1)$ & $29(56.9)$ & \multicolumn{2}{|c|}{$\begin{array}{l}34 \\
18\end{array} 86 / 270(31.9)$} \\
\hline
\end{tabular}

* On these cases no examination were made on the duration of infection.

infection could be done in the non-treated area. As shown in Table 9, it was observed that there was no difference between the values obtained in the first and second periods. It may indicate the consistency of soil-transmitted helminths in an area with this grade of infection. Matsubayashi et al. (1957) reported the same phenomenon in Okutama town adjacent to this area: rate of Trichuris infection was $52.7 \%$ in February 1956, followed by $52.1 \%$ and $58.3 \%, 10$ and 15 months later, respectively. Aida (1962) has reported likewise on this problem. After their extensive survey from 1957 to 1960, Ito, Mochizuki and Noguchi (1966, 1967) reported the epidemiological status of Ascaris and Trichuris infections in Shizuoka Prefecture. The results did not differ greatly from those in this study.

As has been well known, even without treatment, Ascaris infections will spontaneously disappear in about a year. On the other hand, hookworm and Trichuris infections often persist for many years. There is a need for further studies on the countermeasures for the infections with soil-transmitted helminths.

\section{ACKNOWLEDGEMENTS}

The author wishes to express his gratitude to Dr. Y. Komiya, Director of the National Institute of Health, Tokyo, under whose guidance this study was made. The author is also indebted to Dr. T. Ishizaki, Chief of the Department of Parasitology and Dr. T. Yanagisawa and Dr. A. Kobayashi for their helpful discussion on various aspects of this study. Thanks are alsn due to Dr. T. Hara, Mr. I. Yaguchi and Mr. K. Yamamoto, Tokyo Parasite Control Association, for their able technical assistance in the collection and examination of materials and to Messers. Nippon Merck-Banyu Co. Ltd. for the supply of thiabendazole.

\section{REFERENCES}

AIDA, S. (1962): Distribution of the common helminth in Niigata Prefecture. Niigata Med. J., 76, 47-63 (in Japanese).

IsHIZAKI, T. (1953): Clinical studies on ascariasis. I. A new egg-counting method of Ascaris in direct smear specimens. Japan. J. Parasitol., 2, 137-142 (in Japanese).

ITO, J., MochIzUKI, H. AND NOGUCHI, M. (1966): An epidemiologic study of human helminths in rural areas of Shizuoka Prefecture. II. Ascaris lumbricoides and Trichocephalus trichurus. Japan. J. Parasitol., 15, 412-417 (in Japanese). 
ITo, J., MochizUkI, H. AND NoGUCHI, M. (1967): An epidemiologic study of human helminths in rural areas of Shizuoka Prefecture. III. Strongylid nematodes. Japan. J. Parasitol., 16, 8-14 (in Japanese).

KATO, K. AND MiURA, M. (1954): Comparative examinations. Japan. J. Parasitol., 3, 35 (in Japanese).

KATO, K. (1960): A correct application of the thick-smear technic with cellophane cover. A pamphlet, 1-9 (in Japantse),

KomjYA, Y. (1959): Epidemiology of Ascaris infection. "Yakuji-Nippoh," No. 2595-2613 in Japanese).

KomiYa, Y., Kobayashi, A., Kumada, M., Kutsumi, H. AND KoJImA, K. (1960): Study on thick smear technic with cellophane cover for stool examination for helminths ova. Japan. J. Parasitol., 9, 61-68 (in Japanese).

KUTSUMI, H. AND KomiYA, Y. (1965): Effect of thiabendazole as an ovicide on helminth eggs in night-soil. Japan. J. Med. Sci. Biol., 18, 203-224,

Martin, L. K. AND BeAver, P. C. (1967): Evaluation of Kato thick-smear technique for quantitative diagnosis of helminth infections, Am. J. Trop. Med. Hyg., 17, 382-391.

Matsubayashi, H., Abe, M., Saito, S., Iyori, S., Minezaki, I. and KaWabe, F. (1957): Effect of the winter mass treatment of hookworm infections of a community upon the control of the infection, "Koshyu-Eisei," 22, 45-49 (in Japanese).

Watson, J. M. (1960): Medical Helminthology, Bailliere Tindall and Cox, London. 